\title{
Glycemic and Cholesterol Control Versus Single-Goal Control in US Veterans with Newly Diagnosed Type 2 Diabetes: A Retrospective Observational Study
}

\author{
Lizheng Shi $\cdot$ Xin Ye $\cdot$ Mei Lu $\cdot$ Eric Q. Wu $\cdot$ Hari Sharma \\ Darren Thomason · Mengxi Zhang · Yao Wang • Vivian A. Fonseca
}

To view enhanced content go to www.diabetestherapy-open.com

Received: April 22, 2015 / Published online: July 23, 2015

(C) The Author(s) 2015. This article is published with open access at Springerlink.com

\begin{abstract}
Introduction: A majority of patients with diabetes do not have levels of glycated hemoglobin (HbA1c) and low-density lipoprotein cholesterol (LDL-C) under control, either individually or in combination. The objective was to assess the clinical benefits and patient characteristics associated with dual-goal achievement [HbA1c $<7 \%(53 \mathrm{mmol} / \mathrm{mol})$ and LDL-C $<100 \mathrm{mg} / \mathrm{dL}$ ] versus only LDL-C goal achievement in adults with newly diagnosed type 2 diabetes.
\end{abstract}

Methods: Newly diagnosed patients with $\geq 2$ measures of LDL-C and HbA1c were identified in the South Central Veterans Affairs Health Care Network (01/2004-06/2010). The index

Electronic supplementary material The online version of this article (doi:10.1007/s13300-015-0122-2) contains supplementary material, which is available to authorized users.

L. Shi $(\bowtie) \cdot$ M. Zhang · Y. Wang · V. A. Fonseca

Tulane University, New Orleans, LA, USA

e-mail: 1shi1@tulane.edu

X. Ye

Daiichi Sankyo, Inc., Parsippany, NJ, USA

M. Lu - E. Q. Wu · H. Sharma - D. Thomason

Analysis Group, Inc., Boston, MA, USA date was the first HbA1c assessment within 3 months of the first type 2 diabetes diagnosis. Multivariate Cox proportional hazards models were used to assess the association between time-varying goal achievement and post-index microvascular and cardiovascular complications. Patient characteristics associated with dual-goal achievement in the 7-12 months post-index were identified using a logistic regression.

Results: The sample included 16,829 patients. Compared with LDL-C goal achievement, dual-goal achievement was associated with lower risk of microvascular complications [hazard ratio (95\% confidence interval): 0.69 $(0.63,0.76)]$. Other outcomes did not differ between those two groups. Characteristics associated with dual-goal achievement (44.2\% of patients) include prior dual-goal achievement, older age, and use of lipid-lowering drugs.

Conclusion: Dual-goal achievement in newly diagnosed type 2 diabetes is associated with a lower risk of microvascular complications versus only LDL-C goal achievement. Although dual-goal achievement rates are suboptimal, early and regular intervention will increase its likelihood. 
Funding: Daiichi Sankyo, Inc., Parsippany, NJ, USA.

Keywords: Electronic medical records; HbA1c; LDL-C; Type 2 diabetes mellitus; Veterans

\section{INTRODUCTION}

The American Diabetes Association has recommended that the levels of glycated hemoglobin (HbA1c) and low-density lipoprotein cholesterol (LDL-C) in patients with type 2 diabetes be maintained at $<7 \%$ $(53 \mathrm{mmol} / \mathrm{mol})$ and $<100 \mathrm{mg} / \mathrm{dL}$, respectively [1]; however, a majority of patients with diabetes do not have these parameters under control, either individually or in combination [2].

HbA1c control has been shown to be associated with a reduced risk of microvascular complications in the general population of patients with diabetes [3-5] but the evidence is mixed with regards to cardiovascular benefits. Some studies have observed cardiovascular benefits of HbA1c control in relatively less severe patients with diabetes [6-8] or those newly diagnosed with or screened for diabetes [8-10]; however, a recent study on the impact of early use of insulin treatment to normalize glucose levels found no difference in cardiovascular benefits compared with standard treatment [11]. In addition, cardiovascular benefits of LDL-C control in diabetes have been well documented [12-16]. An intensive, multifactorial intervention approach in type 2 diabetes patients, designed to simultaneously target $\mathrm{HbA1c}$, cholesterol levels, and other risk factors, has been shown to significantly reduce the risk of cardiovascular morbidity and mortality, microvascular complications, and rates of cardiovascular surgery $[17,18]$.

The benefits of achieving both HbA1c and LDL-C goals, compared with achieving just one, have not been quantified among newly diagnosed type 2 diabetes patients. Cardiovascular disease is the most frequent cause of death in patients with diabetes [19]. While some studies suggest that tight glycemic control reduces cardiovascular risk in patients who are newly diagnosed with diabetes [9], it is unclear whether achieving the HbA1c goal in addition to the LDL-C goal will have additional cardiovascular benefits. The primary objective of this study was to compare the clinical benefits of dual-goal achievement versus achievement of the LDL-C goal only in patients with newly diagnosed type 2 diabetes. Additional comparisons included dual-goal achievement versus HbA1c goal achievement and no-goal achievement, only LDL-C goal versus no-goal achievement, and only HbA1c goal versus no goal achievement. Furthermore, this study sought to better understand dual-goal achievement status and identify patient characteristics associated with the attainment of both goals.

\section{METHODS}

\section{Data Source}

Electronic medical records from the South Central Veterans Affairs Health Care Network, Veterans Integrated Service Network (VISN) 16 (http://www.visn16.va.gov/) were used in this retrospective observational study. The VISN 16 data warehouse is an integrated, de-identified, individual-level database that includes records for more than 445,000 veterans from 10 medical centers and 40 outpatient clinics in the South 
Central Region of the United States (i.e., Oklahoma, Arkansas, Louisiana, Mississippi, and parts of Texas, Missouri, Alabama, and Florida). The database contains information regarding demographics, vital signs, laboratory results, diagnoses and procedures, inpatient and outpatient services (e.g., admission date, length of stay, emergency room visits), drug prescriptions, and database enrollment history. All data comply with the Health Insurance Portability and Accountability Act (HIPAA). This study was approved by the Institute Review Board including a waiver of informed consent and HIPPA authorization and Research and Development Committee of the Southeast Louisiana Veterans Heath Care System. This article does not contain any studies with human or animal subjects performed by any of the authors.

\section{Sample Selection}

To identify patients who were recently diagnosed with type 2 diabetes mellitus, patients were required to have $\geq 2$ diagnoses of type 2 diabetes mellitus between January 1, 2004 and June 30, 2010, but no such diagnosis for at least 1 year from the start of their enrollment in the database (Fig. 1). Patients with more than 1 diagnosis of type 1 diabetes mellitus were excluded. During the 3-month period surrounding the first type 2 diabetes diagnosis, all patients were required to have at least one measurement of HbA1c and LDL-C within 30 days of each other; the date of the earliest HbA1c measurement in this period was defined as the index date. Patients were required to be $\geq 18$ years old at the time of the index date, be continuously enrolled for at least 12 months, and have $\geq 1$ measurement of both HbA1c and LDL-C in the 7- to 12-month period after the index date. Patients were excluded if they had taken antidiabetic drugs (oral antidiabetic drugs or insulin) or had a measurement of $\mathrm{HbA} 1 \mathrm{c} \geq 7.0 \%(53 \mathrm{mmol} / \mathrm{mol})$ prior to the first diagnosis of type 2 diabetes mellitus or the index date, whichever was earlier.

\section{Data Preparation}

Longitudinal data were analyzed according to 6-month cycles, starting from the index date. Average HbA1c and LDL-C levels were estimated for each cycle using the area under the curve method [20, 21]. For each cycle, the following estimated averages were used to group patients into one of four goal achievement categories: dual-goal [HbA1c $<7 \% \quad(53 \mathrm{mmol} / \mathrm{mol})$ and LDL-C $<100 \mathrm{mg} / \mathrm{dL}$ ], HbA1c only [HbA1c $<7 \%$ (53 mmol/mol) and LDL-C $\geq 100 \mathrm{mg} / \mathrm{dL}], \mathrm{LDL}-\mathrm{C}$ only $[\mathrm{LDL}-\mathrm{C}<100 \mathrm{mg} / \mathrm{dL}$ and HbA1c $\geq 7 \%$ (53 $\mathrm{mmol} / \mathrm{mol})]$, or neither goal $[\mathrm{HbA} 1 \mathrm{c} \geq 7 \%$ (53 $\mathrm{mmol} / \mathrm{mol})$ and LDL-C $\geq 100 \mathrm{mg} / \mathrm{dL}]$.

\section{Patient Characteristics}

Patient characteristics during the first 6-month cycle were summarized for the overall sample as well as stratified by goal achievement status. Demographic information included age at index date, gender, race, body mass index (BMI), and year of index date. The history of diabetes-related complications [microvascular (diabetic retinopathy, neuropathy, or nephropathy), macrovascular (coronary artery disease, cerebrovascular disease, peripheral vascular disease, or atherosclerosis), and other complications such as infection, ocular problems, etc.], comorbidities, and surgical procedures were identified and summarized as of the first cycle using International Classification of Diseases, Clinical Modification, Version 9 (ICD-9-CM) codes. Diabetic medications used by patients during 


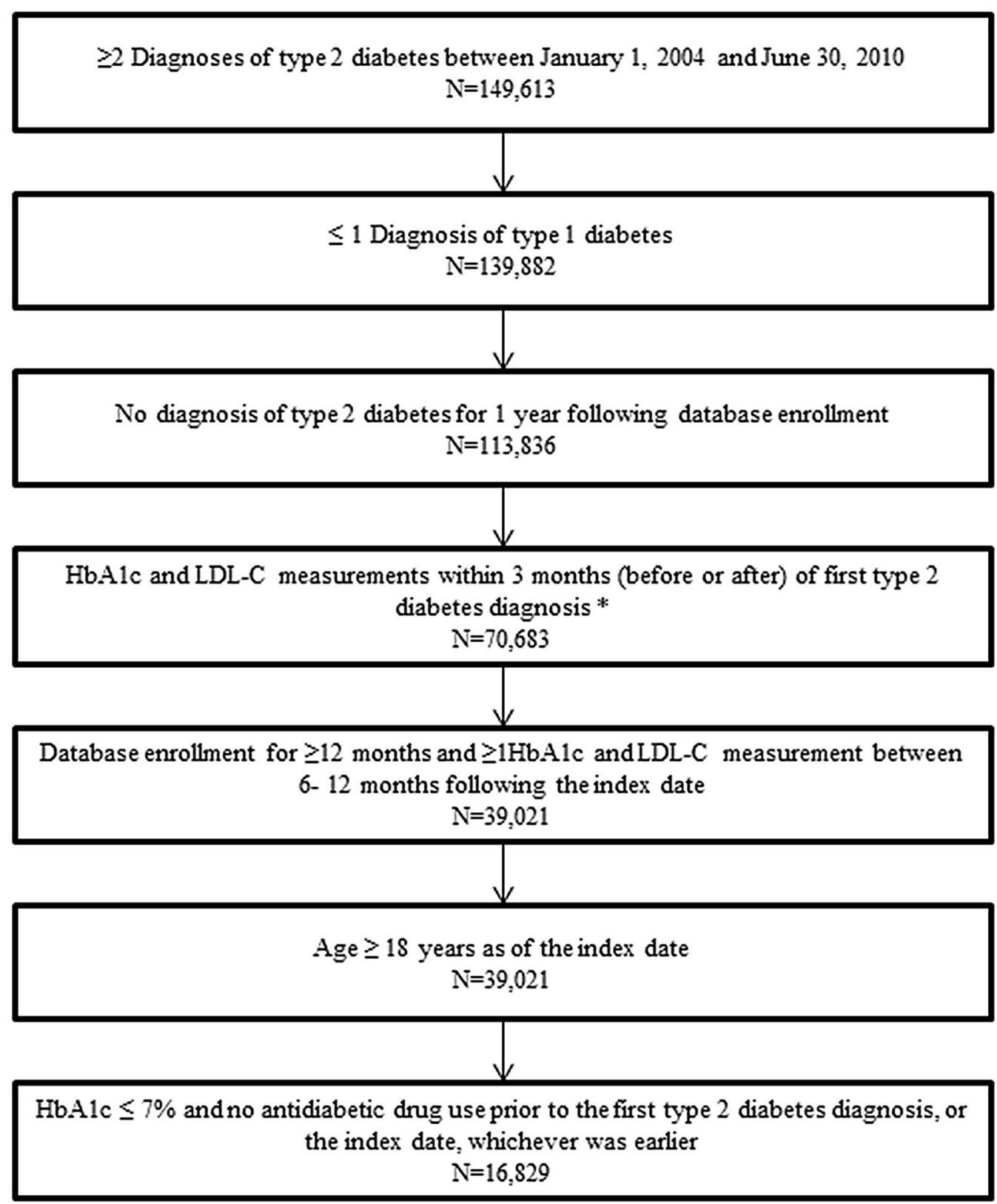

Fig. 1 Sample selection for patients with newly diagnosed type 2 diabetes. Asterisks the date of the earliest HbAlc measurement was considered the index date. HbAlc glycated hemoglobin Alc, $L D L-C$ low-density lipoprotein cholesterol

the first cycle were categorized by drug therapeutic class. Healthcare resource utilization during the first cycle was categorized by inpatient, outpatient, and emergency room (ER) visits. Differences in characteristics between the four patient groups according to goal achievement status were assessed using the analysis of variance method for continuous variables and Chi-squared tests for categorical variables. 


\section{Clinical Outcomes}

Clinical outcomes were selected a priori and included the following: (a) a composite cardiovascular-related endpoint [cerebrovascular disease (stroke), acute myocardial infarction (MI), or cardiovascular death (defined by a diagnosis of coronary artery disease or cerebrovascular disease on the day of death)], (b) acute coronary syndromes (acute MI or unstable angina), (c) a composite endpoint for microvascular complications, and (d) cardiovascular surgical procedures (coronary artery bypass graft or percutaneous coronary intervention) (Supplementary Appendix 1).

For each specific clinical event analyzed, patients were excluded from the analysis if the event occurred before the end of the first cycle, and patients were followed from the start of the second cycle until the first event, death, or end of the data. Cox proportional hazards regression models were used for both descriptive and multivariate analyses. In the descriptive analysis, Cox proportional hazards regression models with time-varying goal achievement status were used to estimate the proportion of patients who did not experience specific clinical events over time. Furthermore, Cox proportional hazards models were expanded in the multivariate analysis to adjust for potential confounding factors: demographics, BMI, and index year as of the index date, cumulative diabetes-related comorbidity/complication history, resource utilization, and medication use. Goal achievement status and confounding factors were measured during a given cycle while the clinical event was measured at the following cycle. The risk of each clinical event by goal achievement status was quantified using adjusted hazard ratios (HRs) with 95\% confidence intervals (95\% CIs).

\section{Characteristics Associated with Dual-Goal Achievement}

To identify characteristics associated with dual-goal achievement 7-12 months after the index date, a logistic regression model was used to assess the effects of individual factors. These include demographics, dual-goal achievement within 6 months following the index date, and complications and comorbidities, diabetic medication use, surgical procedures, resource utilization (i.e., outpatient, inpatient, and ER visits), the Charlson Comorbidity Index (CCI, a validated measure of the overall health status) [22] within the 1-year period surrounding the index date (i.e., 6 months before and 6 months after the index date). The likelihood of achieving both goals relative to not achieving both goals was quantified using adjusted odds ratios (ORs) with 95\% CIs. SAS software version 9.2 (Cary, NC, USA) was used to conduct statistical analyses, and a two-tailed $\alpha$ level of 0.05 was used to determine statistical significance.

\section{RESULTS}

\section{Patient Characteristics}

A total of 16,829 newly diagnosed patients were included in the analysis (Fig. 1). Patient characteristics for the overall population are shown in Table 1 . As of the index date, most patients were over 55 years $(80.8 \%$; mean age 63.3 years), male $(96.8 \%)$, and white $(67.0 \%)$, with a mean BMI of $31.8 \mathrm{~kg} / \mathrm{m}^{2}$. Patients had a history of several diabetes-related complications and comorbidities including hypertension (79.3\%), hyperlipidemia (72.9\%), depression (39.5\%), microvascular complications (19.1\%), macrovascular 


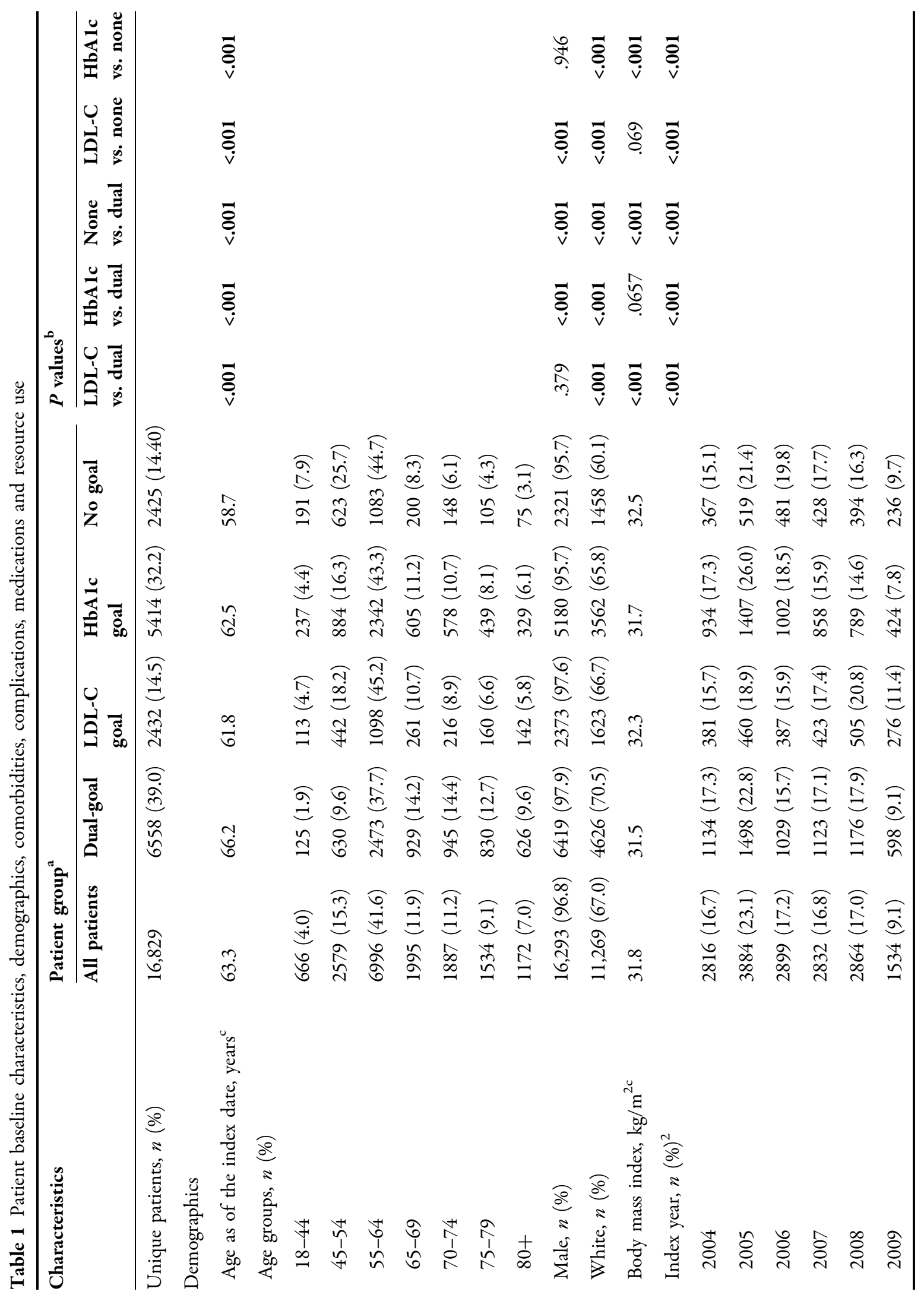




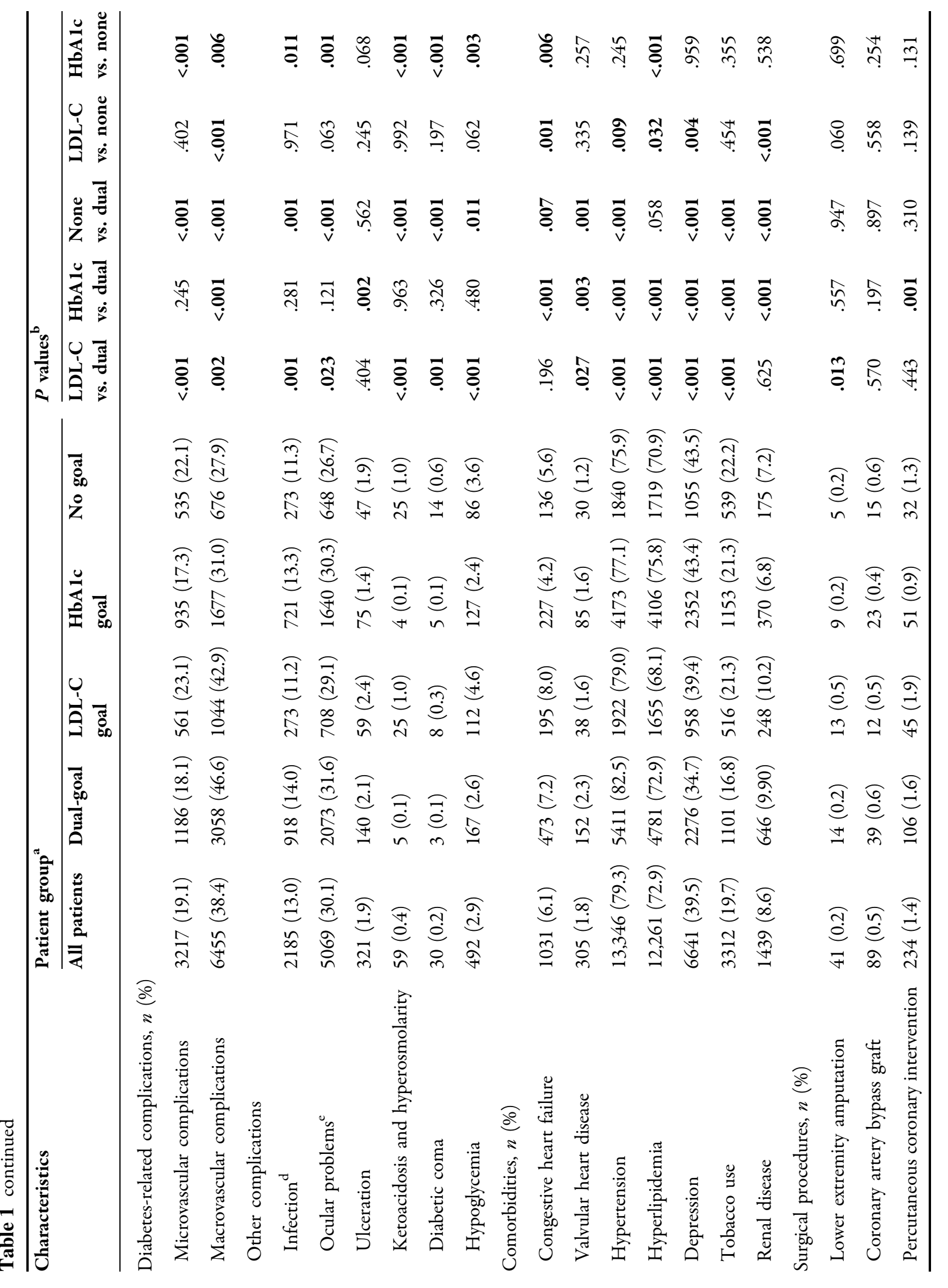




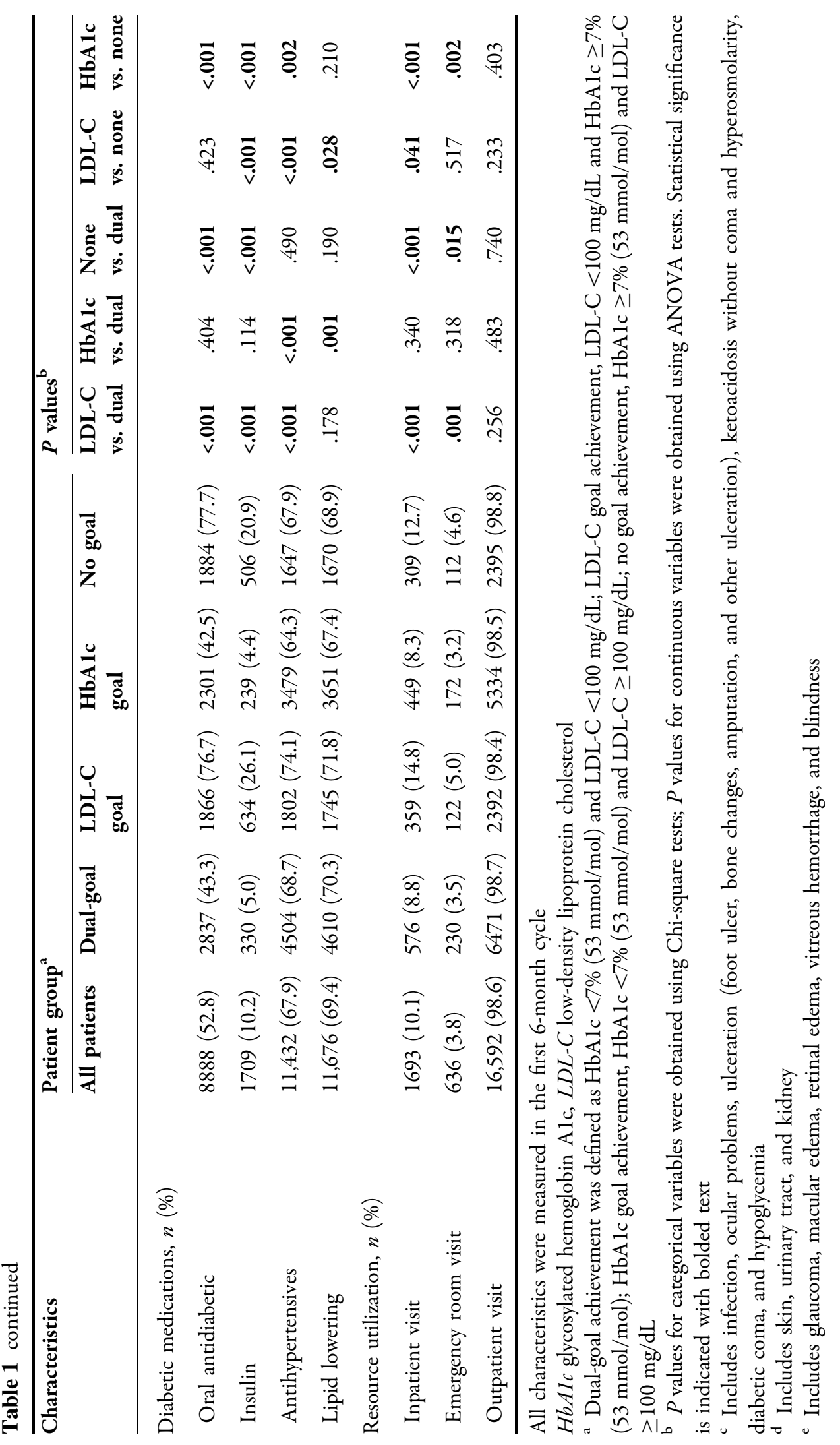


complications (38.4\%), infection (13.0\%), and ocular problems $(30.1 \%)$. The percentages of patients who had undergone lower extremity amputation, coronary artery bypass graft, or percutaneous coronary intervention were 0.2 , 0.5 , and $1.4 \%$, respectively. The majority of patients were taking oral antidiabetic (52.8\%), antihypertensive (67.9\%), and lipid-lowering drugs (69.4\%), while $10.2 \%$ of the patients received insulin during the first 6 months after index date. The majority of the patients had an outpatient visit (98.6\%) during the first 6 months following the index date, but only $3.8 \%$ of the patients had an ER visit; $10.1 \%$ had an inpatient visit during the same period.

During the first 6-month cycle, $39.0 \%$ of patients achieved both goals (dual-goal achievers), while $14.5 \%$ achieved only the LDL-C goal (LDL-C achievers), 32.2\% achieved only the HbA1c goal (HbA1c achievers), and $14.4 \%$ did not achieve either goal (no-goal achievers) (Table 1). Compared with LDL-C achievers, HbA1c achievers, and no-goal achievers, dual-goal achievers were significantly older (66.2 years vs. 61.8, 62.5, and 58.7 for LDL-C, HbA1c, and no-goal achievers, respectively; all $P<.001$ ) and more likely to be white $(70.5 \%$ vs. $66.7 \%, 65.8 \%$, and $60.1 \%$; all $P<.001)$. History of depression was the lowest (34.7\% vs. $39.4 \%, 43.4 \%$, and $43.5 \%$ for LDL-C, HbA1c, and no-goal achievers, respectively; all $P<.001)$ but history of macrovascular complications $(46.6 \%$ vs. 42.9\%, 31.0\%, and 27.9\%; all $P<.001$ ) and hypertension $(82.5 \%$ vs. $79.0 \%, 77.1 \%$, and $75.9 \%$; all $P<.001)$ was the highest for dual-goal achievers compared with other patient groups. History of microvascular complications was lower for dual-goal achievers than LDL-C goal achievers (18.1\% vs. $23.1 \% ; P<.001)$, but similar between dual-goal achievers and HbA1c goal achievers $(18.1 \%$ vs. $17.3 \% ; P=.245)$.

\section{Clinical Outcomes}

The median duration of follow-up time was 3.7 years. Most patients were free of the composite cardiovascular endpoint (96.4, 96.3, 96.6, and 95.9\% for dual-goal, LDL-C, HbA1c, and no-goal achievers, respectively), Acute Coronary Syndrome (ACS) (98.7, 98.2, 98.8, and $98.0 \%)$, or microvascular complications (89.8, 83.5, 89.7, and 84.6\%) during the first year. After 3 years of follow-up, a large majority of patients remained free of the composite cardiovascular endpoint (91.2, 91.0, 91.6, and $90.0 \%$ for dual-goal, LDL-C, HbA1c, and no-goal achievers, respectively), ACS (96.5, 95.2, 96.9, and 94.7\%) or microvascular complications (77.0, 64.6, 76.9, and 66.6\%).

After adjusting for potential confounding factors, the Cox proportional hazards regressions revealed that newly diagnosed diabetes patients who achieved both goals were associated with a lower risk of microvascular complications than patients who achieved only the LDL-C goal or those who did not achieve either goal. In particular, dual-goal achievement was associated with a lower risk of microvascular complications compared with only LDL-C goal achievers [adjusted HR (95\% CI): 0.69 (0.63, 0.76)]. Analyses of all other diabetes-related complications and surgical procedures revealed no other statistically significant benefits for dual-goal achievers relative to single-goal achievers. Compared with no-goal achievers, dual-goal achievers had a significantly decreased risk of experiencing the composite cardiovascular-related endpoint $[0.74$ (0.62, 0.87)], acute coronary syndromes [0.69 (0.54, 


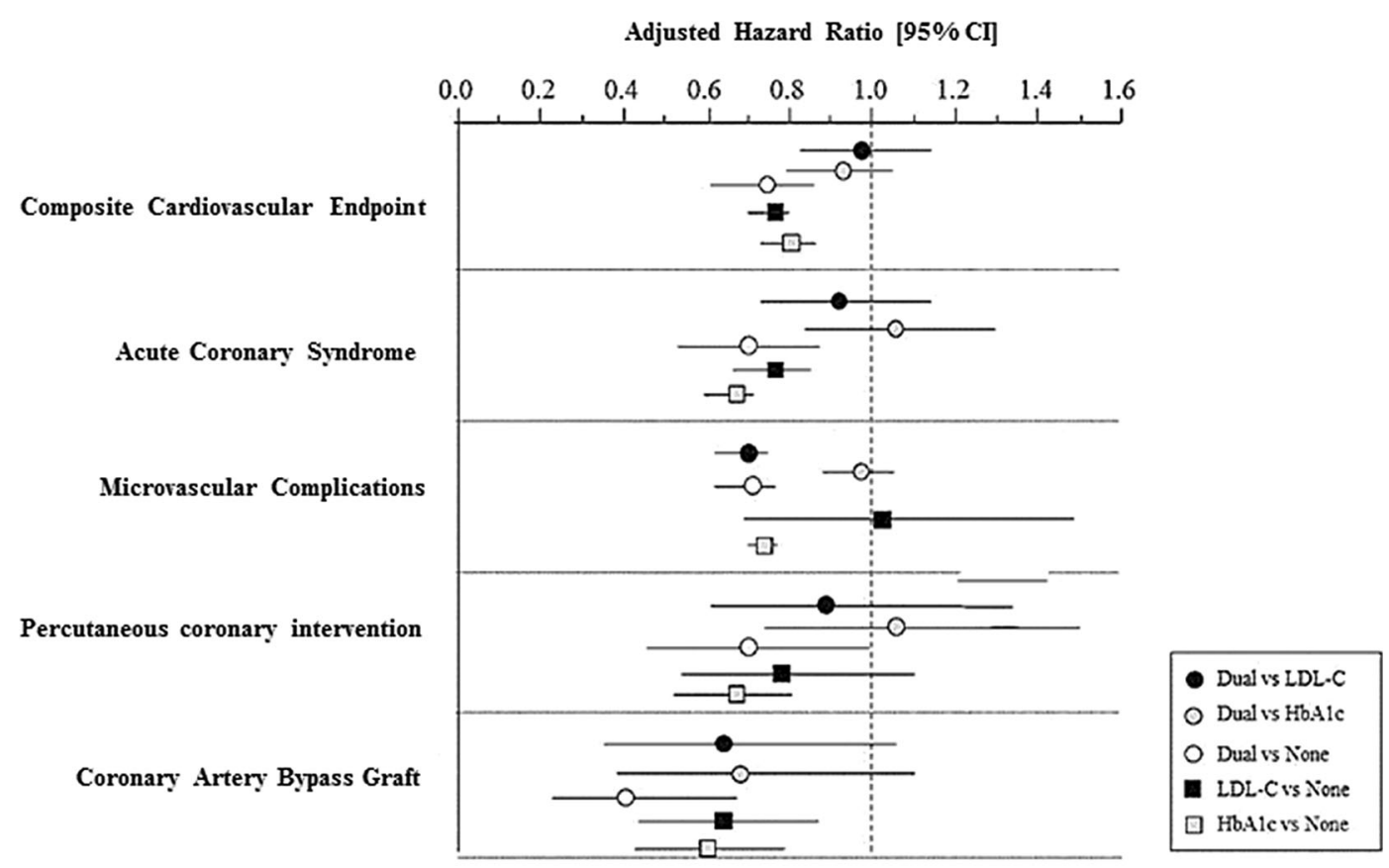

Fig. 2 Risk of experiencing diabetes-related complications and surgeries in patients with newly diagnosed type 2 diabetes. Dual: patients achieving both LDL-C and HbAlc goals; HbAlc: patients achieving only the HbAlc goal;

0.88)], microvascular complications [0.70 (0.63, $0.78)]$, and coronary artery bypass grafting [0.40 (0.23, 0.68)] (Fig. 2).

Compared with no-goal achievers, both groups of single-goal achievers had a significantly lower risk of experiencing composite cardiovascular endpoint [LDL goal achievers: $0.76 \quad(0.71,0.81)$; HbA1c goal achievers: $0.80(0.74,0.87)]$, acute coronary syndrome [LDL goal achievers: 0.76 (0.67, 0.86); HbA1c goal achievers: $0.66(0.60,0.72)]$, and coronary artery bypass grafting [LDL goal achievers: $0.63 \quad(0.45,0.88)$; HbA1c goal achievers: $0.59(0.44,0.80)]$. HbA1c achievers had a lower risk of experiencing microvascular complications $[0.73 \quad(0.71,0.74)], \quad$ and undergoing percutaneous coronary intervention $[0.66(0.53,0.82)]$ relative to no-goal achievers.
LDL-C: patients achieving only the LDL-C goal; none: patients achieving neither goal (please see text for details). $C I$ confidence interval, $H b A l c$ glycated hemoglobin Alc, $L D L-C$ low-density lipoprotein cholesterol

\section{Characteristics Associated with Dual-Goal Achievement}

Out of 16,829 patients, 7432 (44.2\%) achieved dual-goal status while 9397 (55.8\%) were non-dual-goal achievers in the 7-12 months following the index date. The descriptive statistics of characteristics of these patients are summarized in Supplementary Appendix 2. The logistic regression reveals that patient characteristics associated with an increased likelihood of dual-goal achievement included dual-goal achievement during 0-6 months following the index date [adjusted OR (95\% CI): 16.19 (14.92, 17.58)], a diagnosis of ketoacidosis (without coma) and hyperosmolarity $[2.20(1.18,3.94)]$, the use of lipid-lowering drugs $[1.53(1.39,1.69)]$, CCI scores between 1-3 and $\geq 3$ [compared with 
$\mathrm{CCI}=0 ; 1.15(1.03,1.29)$ and $1.40(1.08,1.81)$, respectively], index years of 2007 [1.16 (1.01, 1.33)], 2008 [1.19 (1.04, 1.37)], or 2009 [1.21 $(1.03,1.42)]$ relative to an index year of 2004 , and age $[1.02(1.01,1.02)]$. Conversely, insulin use $[0.70(0.61,0.81)]$ and a diagnosis of retinopathy $[0.67(0.55,0.82)]$, neuropathy [0.85 $(0.76,0.97)]$, or congestive heart failure [0.84 (0.70, 0.99)] were associated with a significantly decreased likelihood of dual-goal achievement (Table 2).

\section{DISCUSSION}

The results from this study show that the achievement of both HbA1c and LDL-C goals in patients with newly diagnosed type 2 diabetes is associated with an additional reduction of microvascular complication rates, compared with achievement of the LDL-C goal alone. The benefit of HbA1c goal has a so-called "glycemic legacy" beyond a finite period of intensive management, as shown in 10-year follow-up of the UKPDS study (ClinicalTrials.gov \# NCT01099865) [9, 23]. In addition, this study found that dual- and single-goal achievements are both generally superior to not achieving either goal, and result in a lower risk of cardiovascular events, acute coronary syndrome, microvascular complications, and cardiovascular surgery. Based on our results, $44.2 \%$ of patients achieved both goals in the 7-12 months following the index date. Prior dual-goal achievement, older age, use of lipid-lowering medication, and prior diagnosis of ketoacidosis (without coma) and hyperosmolarity are associated with an increased likelihood of dual-goal achievement. Conversely, factors associated with a decreased likelihood of dual-goal achievement include retinopathy, neuropathy, congestive heart failure and prior use of insulin.

\section{Benefits of Dual- and Single-Goal Achievements}

The absence of cardiovascular benefits in patients with early-stage type 2 diabetes who achieved dual HbA1c-LDL-C control is consistent with observations available in the literature. In a previous study with a mean follow-up of 5.3 years, an early intensive multifactorial intervention (aimed at reducing HbA1c, LDL-C, and blood pressure) in patients with diabetes mellitus detected by screening was not associated with any statistically significant difference in the rate of cardiovascular events and all-cause mortality, compared with routine care, despite significantly better improvements in HbA1c and LDL-C levels in the intensive treatment group [24]. However, in Steno-2, a randomized study in patients with established diabetes (mean disease duration: 6 years), multifactorial treatment was associated with significantly lower rates of cardiovascular disease and microvascular complications after 7.8 years of follow-up, compared with standard care [17], and further 5.5 years of follow-up demonstrated significant benefits on cardiovascular mortality [18]. In both periods of the Steno-2 study, multifactorial treatment resulted in a higher proportion of patients who achieved HbA1c levels $<6.5 \%(48 \mathrm{mmol} / \mathrm{mol})$ and in mean LDL-C levels $<100 \mathrm{mg} / \mathrm{dL}$ [17, 18]. Taken together, data from our analysis and the studies that assessed the effects of multifactorial intervention $[17,18,24]$ suggest that cardiovascular benefits of dual-goal over single-goal achievements in patients with type 2 diabetes may be observed over a long term. 
Table 2 Characteristics associated with dual-goal achievement

\begin{tabular}{|c|c|c|}
\hline Covariate & Odds ratio $(95 \% \mathrm{CI})^{\mathrm{a}}$ & $P$ value \\
\hline \multicolumn{3}{|l|}{ Demographics } \\
\hline Age & $1.02(1.01,1.02)$ & $<.001$ \\
\hline Male & $0.90(0.73,1.13)$ & .368 \\
\hline Caucasian & $1.01(0.93,1.09)$ & .855 \\
\hline Body mass index & $1.00(0.99,1.01)$ & .821 \\
\hline \multicolumn{3}{|l|}{ Index year } \\
\hline 2005 vs. 2004 & $0.92(0.81,1.05)$ & .203 \\
\hline 2006 vs. 2004 & $1.08(0.94,1.23)$ & .292 \\
\hline 2007 vs. 2004 & $1.16(1.01,1.33)$ & .033 \\
\hline 2008 vs. 2004 & $1.19(1.04,1.37)$ & .010 \\
\hline 2009 vs. 2004 & $1.21(1.03,1.42)$ & .021 \\
\hline \multicolumn{3}{|l|}{ Baseline goal achievement } \\
\hline Dual-goal vs. non-dual-goal & $16.19(14.92,17.58)$ & $<.001$ \\
\hline \multicolumn{3}{|l|}{ Diabetes-related complications } \\
\hline \multicolumn{3}{|l|}{ Microvascular complications } \\
\hline Retinopathy & $0.67(0.55,0.82)$ & .001 \\
\hline Nephropathy & $1.04(0.77,1.39)$ & .806 \\
\hline Neuropathy & $0.85(0.76,0.97)$ & .012 \\
\hline \multicolumn{3}{|l|}{ Macrovascular complications } \\
\hline Atherosclerosis, aneurysm, or embolism & $1.25(0.97,1.60)$ & .085 \\
\hline Peripheral vascular disease & $0.93(0.78,1.12)$ & .453 \\
\hline Cerebrovascular disease & $1.02(0.88,1.19)$ & .784 \\
\hline \multicolumn{3}{|l|}{ Coronary artery disease } \\
\hline Angina & $0.93(0.75,1.16)$ & .545 \\
\hline Myocardial infarction & $0.77(0.48,1.23)$ & .271 \\
\hline \multicolumn{3}{|l|}{ Other complications } \\
\hline Infection $^{\mathrm{b}}$ & $0.94(0.82,1.07)$ & .354 \\
\hline Ocular problems ${ }^{\mathrm{c}}$ & $1.09(1.00,1.19)$ & .060 \\
\hline Ulceration $^{\mathrm{d}}$ & $1.00(0.71,1.39)$ & .982 \\
\hline Ketoacidosis (without coma) and hyperosmolarity & $2.20(1.18,3.94)$ & .010 \\
\hline Hypoglycemia & $1.15(0.90,1.46)$ & .254 \\
\hline
\end{tabular}


Table 2 continued

\begin{tabular}{|c|c|c|}
\hline Covariate & Odds ratio $(95 \% \mathrm{CI})^{\mathrm{a}}$ & $P$ value \\
\hline \multicolumn{3}{|l|}{ Comorbidities } \\
\hline \multicolumn{3}{|l|}{ Cardiovascular disease $^{\mathrm{e}}$} \\
\hline Congestive heart failure & $0.84(0.70,0.99)$ & .043 \\
\hline Valvular heart disease & $1.02(0.76,1.36)$ & .920 \\
\hline Hypertension & $1.12(0.94,1.34)$ & .204 \\
\hline Other cardiovascular disease & $1.08(0.97,1.20)$ & .168 \\
\hline Hyperlipidemia & $0.84(0.70,1.00)$ & .051 \\
\hline Depression & $1.05(0.95,1.15)$ & .366 \\
\hline Renal disease & $1.05(0.88,1.24)$ & .593 \\
\hline Tobacco use & $1.00(0.89,1.12)$ & .949 \\
\hline \multicolumn{3}{|l|}{ Diabetic medications } \\
\hline Oral antidiabetic & $1.06(0.97,1.15)$ & .191 \\
\hline Insulin & $0.70(0.61,0.81)$ & $<.001$ \\
\hline Antihypertensive & $0.94(0.86,1.04)$ & .227 \\
\hline Lipid lowering & $1.53(1.39,1.69)$ & $<.001$ \\
\hline \multicolumn{3}{|l|}{ Surgical procedures } \\
\hline Lower extremity amputation & $0.59(0.22,1.46)$ & .265 \\
\hline Coronary artery bypass graft & $1.22(0.62,2.38)$ & .566 \\
\hline Percutaneous coronary intervention & $0.98(0.63,1.54)$ & .945 \\
\hline \multicolumn{3}{|l|}{ Resource utilization } \\
\hline Outpatient visit & $1.06(0.76,1.49)$ & .726 \\
\hline Urgent care visit $^{\mathrm{f}}$ & $1.04(0.93,1.18)$ & .489 \\
\hline \multicolumn{3}{|l|}{ Charlson Comorbidity Index } \\
\hline $1 \leq \mathrm{CCI}<3$ vs. $\mathrm{CCI}=0$ & $1.15(1.03,1.29)$ & .012 \\
\hline $\mathrm{CCI} \geq 3$ vs. $\mathrm{CCI}=0$ & $1.40(1.08,1.81)$ & .012 \\
\hline
\end{tabular}

Statistical significance is indicated with bolded text

95\% CI 95\% confidence interval, CCI Charlson Comorbidity Index

a Odds ratio $>1$ indicates a higher likelihood of dual-goal achievement (defined as $\mathrm{HbAlc}<7 \%(53 \mathrm{mmol} / \mathrm{mol})$ and LDL-C $<100 \mathrm{mg} / \mathrm{dL}$ ). Goal achievement status was determined at 7-12 months following the index date; covariates were measured in the 1-year period around the index date (i.e., 6 months before and 6 months after). Hosmer and Lemeshow goodness-of-fit test suggested that the model fit well $(P>.05)$

Includes skin, urinary tract, and kidney infections

c Includes glaucoma, macular edema, retinal edema, vitreous hemorrhage, and blindness

d Includes foot ulcer, bone changes, amputation, and other ulcerations

e Excludes macrovascular complications

${ }^{\mathrm{f}}$ Includes emergency room and inpatient visits 
Possibly, a follow-up time of 3.7 years in our study was not sufficient to reveal such benefits. The 1- and 3-year cumulative cardiovascular event-free rates (96.4\%, and 91.2\%, respectively) among patients with dual-goal achievement in our study were similar to patients with intensive treatment in the Steno-2 study (approximately 97.8\% and $87.5 \%$ by year 1 and 3, respectively) [18].

The observed cardiovascular benefits of single-goal achievement (HbA1c or LDL-C) versus no-goal achievement are also consistent with literature [25-27].

\section{Status and Characteristics Associated with Dual-Goal Achievement}

Given that, only $44.2 \%$ of patients achieved both the HbA1c and LDL-C goals in the 7-12 month period following the index date, our results suggest an unmet need in controlling major risk factors for patients with newly diagnosed diabetes. This is consistent with available literature [2].

Our results also show that prior dual-goal achievement, older age, and the use of lipid-lowering drugs are associated with dual-goal achievement. On the contrary, insulin use and diabetes-related complications such as neuropathy, retinopathy, and congestive heart failure, which indicate a more advanced phase of the disease, are identified as characteristics associated with a decreased likelihood of dual-goal achievement. These results highlight the importance of timely intervention and regular medical care in achieving HbA1c and LDL-C goals.

These results are consistent with findings from several other studies. Older age was associated with the achievement of $\mathrm{HbA1c}$ goal in a recent retrospective cohort study of individuals with type 2 diabetes [28] and with the achievement of simultaneous glycemic, lipid, and blood pressure control in patients with diabetes, hypercholesterolemia, and hypertension [29]. In addition, a recently presented conference proceeding of a retrospective cohort study found that patients with diabetes who attained HbA1c levels $<7 \%$ (53 mmol/mol) were generally older and less likely to receive insulin than patients who had not achieved HbA1c goal [30]. The Look AHEAD study (ClinicalTrials.gov \# NCT00017953) suggested that insulin use and non-utilization of lipid-lowering drugs was associated with a failure to achieve all three goals (HbA1c, LDL-C, and blood pressure) among overweight and obese patients with diabetes [31]. Finally, achievement of the LDL-C goal has been directly associated with older age, and inversely associated with baseline LDL-C [32].

\section{Limitations and Strengths}

Due to the retrospective observational design, the analysis may have been affected by unobserved differences that were not taken into account in the model. Although we used strict selection criteria, there is a possibility we included some patients who were not truly newly diagnosed with T2DM. Specifically, we observed an unexpectedly high rate of insulin use during the 6-month post-index period. Patients who did not achieve either goal were on average about 8 years younger and used 4 times more insulin than those who achieved both goals (20.9\% vs. $5.0 \%)$. It is possible that some of these younger patients who were using insulin were suffering from latent autoimmune diabetes of adults instead of type 2 diabetes [33]. In addition, some important information was not captured in the electronic medical records, including disease severity, disease duration, lifestyle modifications, and any potential (but 
unlikely) health care services that were provided outside of the Veterans Affairs (VA) health system. We did not look into the specific information about alternative cholesterol-lowering drugs and antihypertensive drugs. Furthermore, the VA database predominantly consists of male patients, which may limit generalization of findings. One of the major advantages of using electronic records from VA health system is that the lab values are recorded over time, allowing for a longitudinal study design with a median follow-up period of 3.7 years.

Similar studies in the general population, designed to assess the effects of medication, lifestyle changes, or triple-goal achievement (HbA1c, LDL-C, and blood pressure) may provide additional information. In addition, analyses with longer follow-up times may reveal benefits of dual- or triple-goal achievements on cardiovascular outcomes that were not observed in this study.

\section{CONCLUSION}

In US veterans with a newly recorded diagnosis of type 2 diabetes, the main benefit of achieving both HbA1c and LDL-C goals over achieving only LDL-C goal appears to be a reduced rate of microvascular complications. However, current rates of dual-goal achievement are suboptimal. Prior dual-goal achievement and use of lipid-lowering drugs were both associated with a higher rate of dual-goal achievement, which highlights the importance of early intervention and regular medical care.

\section{ACKNOWLEDGMENTS}

We wish to thank the Department of Veterans Affairs VISN 16 Data warehouse for the de-identified dataset and the Southeast Louisiana Veterans Health Care System for additional resources. The contents of this presentation do not represent the views of the Department of Veterans Affairs or the United States Government. Drs. Joy Ramos, Biplob Dass, Vojislav Pejović, and Michael Miller from Prescott Medical Communications Group (Chicago, IL) provided medical research and editorial assistance which was funded by Daiichi Sankyo, Inc., Parsippany, NJ, USA. Sponsorship and article processing charges for this study were funded by Daiichi Sankyo, Inc., Parsippany, NJ, USA. All named authors meet the International Committee of Medical Journal Editors (ICMJE) criteria for authorship for this manuscript, take responsibility for the integrity of the work as a whole, and have given final approval for the version to be published.

Disclosures. Lizheng Shi, Vivian A Fonseca, Yao Wang, and Mengxi Zhang declare that they have no conflict of interest. Mei Lu, Eric Q Wu, Hari Sharma, and Darren Thomason are employees at Analysis Group, Inc. and have received funding from Daiichi Sankyo, Inc. Xin Ye is an employee of Daiichi Sankyo, Inc. The data used in this manuscript were presented at the Epidemiology and Prevention: Nutrition, Physical Activity and Metabolism 2013 Scientific Sessions on March 19-22 in New Orleans, LA.

Compliance with ethics guidelines. This article does not contain any studies with human or animal subjects performed by any of the authors.

Open Access. This article is distributed under the terms of the Creative Commons Attribution Noncommercial License which permits any noncommercial use, distribution, 
and reproduction in any medium, provided the original author(s) and the source are credited.

\section{REFERENCES}

1. Inzucchi SE, Bergenstal RM, Buse JB, Diamant M, Ferrannini E, Nauck M, et al. Management of hyperglycemia in type 2 diabetes, 2015: a patient-centered approach: update to a position statement of the American Diabetes Association and the European Association for the Study of Diabetes. Diabetes Care. 2015;38:140-9.

2. Malik S, Lopez V, Chen R, Wu W, Wong ND. Undertreatment of cardiovascular risk factors among persons with diabetes in the United States. Diabetes Res Clin Pract. 2007;77:126-33.

3. Chew EY, Ambrosius WT, Davis MD, Danis RP, Gangaputra S, Greven CM, et al. Effects of medical therapies on retinopathy progression in type 2 diabetes. N Engl J Med. 2010;363:233-44.

4. Ismail-Beigi F, Craven T, Banerji MA, Basile J, Calles $\mathrm{J}$, Cohen RM, et al. Effect of intensive treatment of hyperglycaemia on microvascular outcomes in type 2 diabetes: an analysis of the ACCORD randomised trial. Lancet. 2010;376:419-30.

5. Patel A, MacMahon S, Chalmers J, Neal B, Billot L, Woodward M, et al. Intensive blood glucose control and vascular outcomes in patients with type 2 diabetes. N Engl J Med. 2008;358:2560-72.

6. Skyler JS, Bergenstal R, Bonow RO, Buse J, Deedwania P, Gale EA, et al. Intensive glycemic control and the prevention of cardiovascular events: implications of the ACCORD, ADVANCE, and VA diabetes trials: a position statement of the American Diabetes Association and a scientific statement of the American College of Cardiology Foundation and the American Heart Association. Diabetes Care. 2009;32:187-92.

7. Wang CC, Reusch JE. Diabetes and cardiovascular disease: changing the focus from glycemic control to improving long-term survival. Am J Cardiol. 2012;110:58B-68B.

8. Lauritzen T, Borch-Johnsen K, Davies MJ, Khunti K, Rutten GEHM, Sandbæk A, et al. Screening for diabetes: what do the results of the ADDITION trial mean for clinical practice? Diabetes Manag. 2013;3:367-78.

9. Holman RR, Paul SK, Bethel MA, Matthews DR, Neil HA. 10-year follow-up of intensive glucose control in type 2 diabetes. N Engl J Med. 2008;359:1577-89.
10. King P, Peacock I, Donnelly R. The UK Prospective Diabetes Study (UKPDS): clinical and therapeutic implications for type 2 diabetes. $\mathrm{Br} \mathrm{J}$ Clin Pharmacol. 1999;48:643-8.

11. The ORIGIN Trial Investigators. Basal insulin and cardiovascular and other outcomes in dysglycemia. N Engl J Med. 2012;367:319-28.

12. Colhoun HM, Betteridge DJ, Durrington PN, Hitman GA, Neil HA, Livingstone SJ, et al. Primary prevention of cardiovascular disease with atorvastatin in type 2 diabetes in the Collaborative Atorvastatin Diabetes Study (CARDS): multicentre randomised placebo-controlled trial. Lancet. 2004;364:685-96.

13. Collins R, Armitage J, Parish S, Sleigh P, Peto R. MRC/BHF Heart Protection Study of cholesterol-lowering with simvastatin in 5963 people with diabetes: a randomised placebo-controlled trial. Lancet. 2003;361:2005-16.

14. Goldberg RB, Mellies MJ, Sacks FM, Moye LA, Howard BV, Howard WJ, et al. Cardiovascular events and their reduction with pravastatin in diabetic and glucose-intolerant myocardial infarction survivors with average cholesterol levels: subgroup analyses in the cholesterol and recurrent events (CARE) trial. The Care Investigators. Circulation. 1998;98:2513-9.

15. Sever PS, Poulter NR, Dahlöf B, Wedel H, Collins R, Beevers $\mathrm{G}$, et al. Reduction in cardiovascular events with atorvastatin in 2532 patients with type 2 diabetes: Anglo-Scandinavian Cardiac Outcomes Trial-lipid-lowering arm (ASCOT-LLA). Diabetes Care. 2005;28:1151-7.

16. Shepherd J, Barter P, Carmena R, Deedwania P, Fruchart JC, Haffner S, et al. Effect of lowering LDL cholesterol substantially below currently recommended levels in patients with coronary heart disease and diabetes: the Treating to New Targets (TNT) study. Diabetes Care. 2006;29:1220-6.

17. Gaede P, Vedel P, Larsen N, Jensen GV, Parving HH, Pedersen O. Multifactorial intervention and cardiovascular disease in patients with type 2 diabetes. N Engl J Med. 2003;348:383-93.

18. Gaede P, Lund-Andersen H, Parving HH, Pedersen O. Effect of a multifactorial intervention on mortality in type 2 diabetes. $\mathrm{N}$ Engl J Med. 2008;358:580-91.

19. Morrish NJ, Wang SL, Stevens LK, Fuller JH, Keen H. Mortality and causes of death in the WHO Multinational Study of vascular disease in Diabetes. Diabetologia. 2001;44(Suppl 2):S14-21. 
20. Rohlfing CL, Wiedmeyer HM, Little RR, England JD, Tennill A, Goldstein DE. Defining the relationship between plasma glucose and $\mathrm{HbA}(1 \mathrm{c})$ : analysis of glucose profiles and $\mathrm{HbA}(1 \mathrm{c})$ in the Diabetes Control and Complications Trial. Diabetes Care. 2002;25:275-8.

21. Tai MM. A mathematical model for the determination of total area under glucose tolerance and other metabolic curves. Diabetes Care. 1994;17:152-4.

22. Charlson M, Szatrowski TP, Peterson J, Gold J. Validation of a combined comorbidity index. J Clin Epidemiol. 1994;47:1245-51.

23. Murray P, Chune GW, Raghavan VA. Legacy effects from DCCT and UKPDS: what they mean and implications for future diabetes trials. Curr Atheroscler Rep. 2010;12:432-9.

24. Griffin SJ, Borch-Johnsen K, Davies MJ, Khunti K, Rutten GE, Sandbaek A, et al. Effect of early intensive multifactorial therapy on 5-year cardiovascular outcomes in individuals with type 2 diabetes detected by screening (ADDITION-Europe): a cluster-randomised trial. Lancet. 2011;378:156-67.

25. American Diabetes Association. Standards of medical care in diabetes-2012. Diabetes Care. 2012;35(Suppl 1):S11-63.

26. Bailey CJ, Del Prato S, Eddy D, Zinman B. Earlier intervention in type 2 diabetes: the case for achieving early and sustained glycaemic control. Int J Clin Pract. 2005;59:1309-16.
27. Steinmetz A. Lipid-lowering therapy in patients with type 2 diabetes: the case for early intervention. Diabetes Metab Res Rev. 2008;24:286-93.

28. Wu N, Aagren M, Boulanger L, Friedman M, Wilkey K. Assessing achievement and maintenance of glycemic control by patients initiating basal insulin. Curr Med Res Opin. 2012;28(10):1647-56.

29. Schroeder EB, Hanratty R, Beaty BL, Bayliss EA, Havranek EP, Steiner JF. Simultaneous control of diabetes mellitus, hypertension, and hyperlipidemia in 2 health systems. Circ Cardiovasc Qual Outcomes. 2012;5:645-53.

30. Schroeder EB, Bayliss EA, Newcomer SR, Steiner JF. Abstract P109: predictors of hemoglobin A1C trajectories in a cohort of patients with diabetes. Circ Cardiovasc Qual Outcomes. 2011;4:AP109.

31. Bertoni AG, Clark JM, Feeney P, Yanovski SZ, Bantle J, Montgomery B, et al. Suboptimal control of glycemia, blood pressure, and LDL cholesterol in overweight adults with diabetes: the Look AHEAD Study. J Diabetes Complicat. 2008;22:1-9.

32. Park JE, Chiang CE, Munawar M, Pham GK, Sukonthasarn A, Aquino AR, et al. Lipid-lowering treatment in hypercholesterolaemic patients: the CEPHEUS Pan-Asian survey. Eur J Prev Cardiol. 2012;19:781-94.

33. Stenstrom G, Gottsater A, Bakhtadze E, Berger B, Sundkvist G. Latent autoimmune diabetes in adults: definition, prevalence, beta-cell function, and treatment. Diabetes. 2005;54(Suppl 2):S68-72. 